\title{
AS AÇÕES AFIRMATIVAS E O ACESSO DOS QUILOMBOLAS À EDUCAÇÃO SUPERIOR
}

\author{
AFFIRMATIVE ACTIONS AND ACCESS FROM QUILOMBOLES TO HIGHER \\ EDUCATION
}

\author{
Eglantina Alonso Braz \\ Mestra em Desenvolvimento Territorial e Gestão Social \\ Universidade Federal da Bahia - UFBA. \\ Salvador, Bahia - Brasil. \\ eab0206@gmail.com \\ Daiane da Luz Silva \\ Mestra em Estudos Interdisciplinares sobre a Universidade \\ Universidade Federal da Bahia - UFBA \\ Salvador, Bahia - Brasil \\ daiane@ufba.br \\ Elizabeth Matos Ribeiro \\ Doutora em Ciências Políticas e Administração \\ Universidade Federal da Bahia - UFBA. \\ Salvador, Bahia - Brasil. \\ ematos@ufba.br
}

\begin{abstract}
Resumo: As políticas de ações afirmativas no Brasil nas últimas décadas estão exercendo função primordial como recurso facilitador da democratização do acesso à Educação Superior, principalmente para a inclusão de grupos étnicos sub-representados. Nesse contexto, o presente estudo tem por objetivo analisar o acesso à conclusão e à evasão, bem como os cursos e as áreas de maior interesse dos estudantes remanescentes de quilombos na Universidade Federal da Bahia (UFBA) que ingressaram por meio de cotas raciais, para identificar os resultados da adoção das ações afirmativas específicas para esse público nessa instituição. Trata-se de uma pesquisa descritiva, quali-quantitativa, de tipo documental. Para tanto, foram analisados os dados de acesso e permanência aos cursos de graduação a partir da implementação das cotas raciais para os remanescentes de quilombo ingressos de 2005 até o semestre 2019.1 . Os resultados apontaram que o número de acesso à Universidade por parte desse público aumentou nos últimos anos, que as preferências são para as carreiras das áreas de saúde e humanas, com mais matriculados nos cursos de Farmácia, Enfermagem, Medicina e Letras e que o número de evasão é baixo, em comparação com uma taxa de conclusão exitosa. A maior taxa de ocupação das vagas em cursos que formam profissionais em carreiras historicamente ocupadas pelas elites denota que as ações afirmativas estão gerando significativas transformações sociais, que pode levar à reparação histórica, ao reconhecimento e à valorização política, cultural e de identidade dos quilombolas.
\end{abstract}

Palavras-chave: universidade; ações afirmativas; quilombolas; estudo de caso.

Abstract. As affirmative action policies in Brazil, in the last decades, they have been exercising primary function or facilitating resource of democratization of access to Higher Education, mainly for the inclusion of underrepresented ethnic groups. In this context, the present study aims to analyze access, completion, and evasion, as well as the courses and areas of greatest interest of remaining students from quilombos at the Federal University of Bahia (UFBA), who entered through racial quotas, to identify the results of the adoption of specific affirmative actions for this audience in this institution. This is descriptive, qualitative-quantitative, documentarytype research. To this end, data on access and permanence to undergraduate courses were analyzed based on the implementation of racial quotas for quilombo remnants who entered from 2005 to semester 2019.1. The results showed that the number of accesses to the University by them has increased in recent years, that the preferences are for careers in the areas of health and humanities, with more enrollments in the courses of Pharmacy, Nursing, Medicine and Languages and that the number of dropouts is low compared to a successful completion rate. The higher occupancy rate of vacancies in courses that train professionals in careers historically occupied by the elites denotes those affirmative actions are generating significant social transformations, which can lead to historical repair, recognition and the political, cultural and identity enhancement of the quilombolas.

Keywords: university; affirmative actions; quilombolas; case study.

Para citar - (ABNT NBR 6023:2018)

BRAZ, Eglantina Alonso; SILVA, Daiane da Luz; RIBEIRO, Elizabeth Matos. As ações afirmativas e o acesso dos quilombolas à educação superior. Eccos - Revista Científica, São Paulo, n. 58, p. 1-17, e17335, jul./set. 2021. Disponível em: https://doi.org/10.5585/eccos.n58.17335. 


\section{Introdução}

O Brasil é um país multiétnico e miscigenado, resultado de um processo sócio-histórico de formação da população, decorrido por causa da colonização e da imigração. Como todo processo de colonização, os efeitos nocivos para os povos colonizados geram profundas desigualdades.

No caso brasileiro, o sistema escravagista, que atuou contra a existência e dignidade dos povos indígenas e africanos, formou abismos sociais, reforçados cotidianamente pela segregação e discriminação desses povos e seus descendentes, cujo produto resultou no racismo em todas as suas dimensões (CAMPOS, 2017). A ideia de raça, aplicada ao contexto histórico e social na América, foi pautada como referência a supostas estruturas biológicas de diferença entre colonizadores e colonizados, também significou a legitimação de ideias e práticas de superioridade/inferioridade entre dominantes e dominados (QUIJANO, 2005). Para Quijano (2005), a formação de relações sociais fundadas nessa ideia, produziu as identidades sociais indígenas, negras, mestiças, entre outras. Segundo ele, essas identidades foram associadas às hierarquias e papéis sociais correspondentes ao padrão de dominação que se impunha, mas, sobretudo, outorgou a legitimidade das relações de dominação impostas pela colonização.

Uma possibilidade de alterar esse quadro de discriminação, para Campos (2017), são as ações afirmativas em vigor no Brasil, pois são instrumentos que visam alterar o caráter racista das estruturas sociais, proporcionando a alteração dos lugares historicamente ocupados pelos grupos sub-representados e os conduzindo a espaços de privilégio e poder. Neste sentido, as ações afirmativas adotadas na última década como forma de acesso à educação superior têm essa finalidade, uma vez que, as instituições que a ofertam historicamente são redutos da elite branca. Ao dar acesso aos mais vulneráveis, as ações afirmativas estariam colaborando para uma transformação positiva da sociedade, tornando-a mais justa e democrática (DINIZPEREIRA; SOARES, 2019).

Por essa razão, esse estudo tem por objetivo analisar as taxas de acesso, conclusão e evasão, bem como os cursos e áreas de maior interesse dos estudantes remanescentes das comunidades quilombolas na Universidade Federal da Bahia (UFBA), que ingressaram por meio de cotas raciais, para identificar os resultados da adoção das ações afirmativas específicas para esse público nessa instituição.

A UFBA, desde 2004, oferta cotas nas vagas de seus cursos de graduação para o grupo étnico citado, considerando que tratam-se de meios possíveis de reduzir as desigualdades sociais e raciais, resultado da inclusão desse público no âmbito universitário. Acredita-se, 
portanto, que as ações afirmativas, por sua finalidade, tornam-se um instrumento de inclusão e o êxito de sua implantação é uma importante possibilidade para o alcance da democratização do acesso à educação superior.

\section{A inclusão das ações afirmativas na UFBA}

A Lei 12.711/2012 determinou que as Universidades, Institutos e Centros Federais de educação reservem $50 \%$ das suas vagas para estudantes oriundos de escola pública, estabelecendo um percentual, dentro dessa reserva, para estudantes negros, autodeclarados pardos ou pretos, e indígenas. Contudo, anterior a essa lei, algumas universidades já vinham adotando as cotas como política pública de ação afirmativa. A primeira universidade a aderir ao programa de cotas no Brasil foi a Universidade Estadual do Rio de Janeiro (UERJ), em 2003. A partir daí, o número de adesão cresceu rapidamente.

O Sistema geral de cotas está também associado a cotas sociais, que consistem na reserva de vagas para pessoas que vêm de escolas públicas, pessoas com algum tipo de deficiência, estudantes com baixa renda familiar. As cotas raciais, como parte de uma política de ações afirmativas, têm sido um mecanismo que permite o acesso ao ensino superior de uma parcela historicamente excluída da população.

Na UFBA, as cotas sociais e raciais foram implementadas pelo Conselho de Ensino, Pesquisa e Extensão (CONSEPE/UFBA) em julho de 2004 e previa cotas para oriundos de escolas públicas e raciais, sendo 02 (duas) vagas, além do número de vagas estabelecido para o curso, sendo cada uma para indígenas e aldeados ou moradores das comunidades remanescentes dos quilombos, que tenham cursado a partir da segunda etapa do ensino fundamental até a conclusão do ensino médio integralmente em escolas públicas (UFBA, 2004; 2012).

A comunidade acadêmica tem nos últimos anos buscado ampliar a oferta de vagas para atendimento aos grupos sub-representados e dos que se enquadram na categoria de vulnerabilidade social. Entre eles, os moradores de comunidades quilombolas, que segundo estudo recente publicado pela Associação Nacional dos Dirigentes das Instituições Federais de Ensino Superior (ANDIFES), tem acessado cada vez mais a graduação. Ela identificou que dentro do período de 4 anos (2014 a 2018), o número de estudantes quilombolas que eram de 4.231, em 2018 contavam com 10.747. A mesma pesquisa também identificou a situação de vulnerabilidade social desses estudantes, considerando que, do total de estudantes cotistas, os remanescentes de quilombos e os indígenas aldeados são os que possuem menor renda, chegando a ter cerca de $50 \%$ equivalente ao valor da renda per capita de um preto não- 
quilombola (ANDIFES, 2019). Esses dados ratificam a necessidade da política ações afirmativas no tocante não somente à inclusão desse público, mas, também, à adoção de medidas que possam favorecer a permanência deles nos espaços acadêmicos de formação superior.

\section{Os remanescentes das comunidades quilombolas}

O processo de escravização dos africanos trazidos para o Brasil foi um dos momentos mais trágicos e danosos da história da população mundial. Mas apesar de todo um sistema que insistia em subjugá-los, houve muita luta e resistência. Um símbolo desse processo foi o quilombo. Os quilombos representam resistência e luta contra a forma de repressão vivenciada por esses africanos e seus descendentes ao longo da história, tendo insurgido diante de uma situação de conflito entre escravagistas e escravizados. Fugir das agruras da escravidão e refugiar-se em um quilombo era a possibilidade de ter liberdade e uma vida mais digna. Assim, o quilombo tornou-se um núcleo paralelo de poder, organização social e produção para a própria subsistência (FURTADO; PEDROZA; ALVES, 2014). Hoje em dia nas comunidades remanescentes de quilombo vivem aqueles que descendem desses povos escravizados.

Legalmente, aos remanescentes de quilombo foi reconhecido o direito à terra. No art. 68 do Ato das Disposições Constitucionais Transitórias, definiu-se que "Aos remanescentes das comunidades dos quilombos que estejam ocupando suas terras é reconhecida a propriedade definitiva, devendo o Estado emitir-lhes os títulos respectivos”. O Decreto 4.887/2003 define em seu art. $2^{\circ}$, que são remanescentes das comunidades quilombolas: “[...] os grupos étnicoraciais, segundo critérios de autoatribuição, com trajetória histórica própria, dotados de relações territoriais específicas, com presunção de ancestralidade negra relacionada com a resistência à opressão histórica sofrida". E conceituou, no $\S 2^{\circ}$ do art. $2^{\circ}$, que: "São terras ocupadas por remanescentes das comunidades dos quilombos as utilizadas para a garantia de sua reprodução física, social, econômica e cultural". Possibilitando-lhes assim, o direito à autodeterminação.

Atualmente no Brasil, há 3.475 Comunidades Remanescentes de Quilombo (CRQ), devidamente certificadas pela Fundação Cultural Palmares (FCP), instituição vinculada ao Ministério da Cidadania (Fundação Cultural Palmares, 2021). A região Nordeste é onde está concentrada a maior parte das Comunidades Remanescentes de Quilombo (CRQ), com cerca 2.196 CRQ, ou seja, 63\% do total. A segunda região com maior CRQ é a região Sudeste com 547 comunidades certificadas, seguida da região Norte com 369, depois a região Sul com 193 e por último a região Centro-Oeste com 169 CRQ, conforme demonstrado no gráfico 1. Destas, 
somente na Bahia há 827 comunidades quilombolas reconhecidas, apesar de um expressivo declínio nos processos de reconhecimento das CRQ desde 2019, conforme demonstrativo indicado pela Fundação Cultural Palmares (2021).

\section{Gráfico 1 - Comparativo das Comunidades Remanescentes de Quilombo (CRQ) entre as Regiões}

\section{CRQs reconhecidas por região}

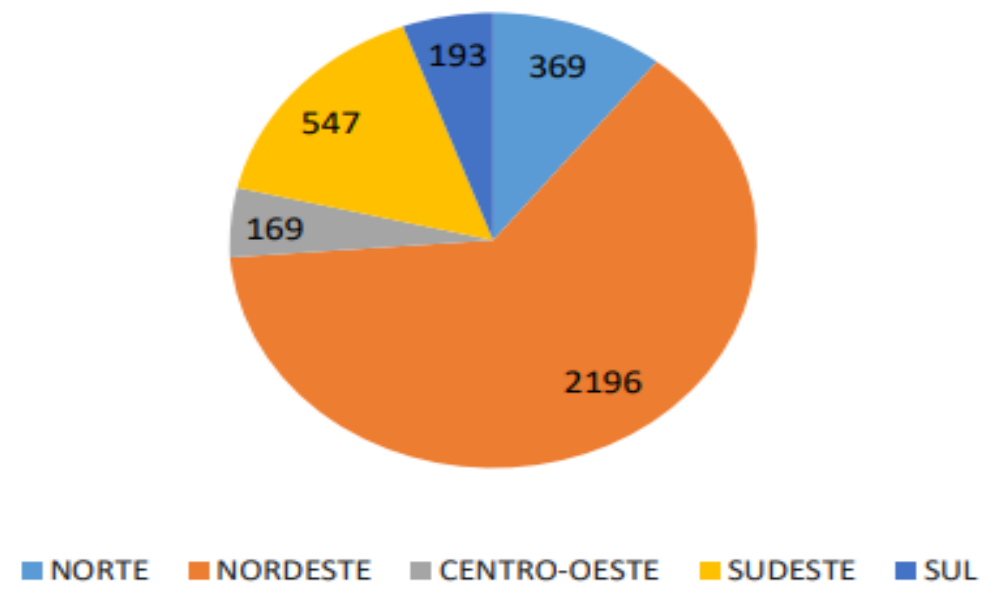

Fonte: Fundação Cultural Palmares (2021).

Todavia, os remanescentes de quilombo continuam em busca por igualdade de oportunidades, considerando que os territórios quilombolas, mesmo os que estão em áreas urbanas, persistem em condições precárias, com pouco ou nenhum investimento público em saneamento, saúde, educação e moradia dignos. O reconhecimento dessas comunidades tradicionais é imprescindível para que a justiça social possa prevalecer, inclusive no que tange ao acesso à educação.

\subsection{Ações inclusivas na educação quilombola.}

Os remanescentes quilombolas permanecem na luta por seus direitos civis, como a terra, a qualidade de vida, a saúde, mas também reivindicam seus direitos à educação de qualidade, a partir dos quais possam desenhar um futuro melhor para as comunidades, alcançando o ensino

superior. É preciso ações governamentais para a efetivação das políticas educacionais inclusivas. A Coordenação Nacional de Articulação das Comunidades Negras Rurais Quilombolas (CONAQ) e o movimento negro vêm denunciando esse descaso com a educação pública. 
Em 2003, o governo federal implementou alguns avanços efetivos para a reparação com as comunidades quilombolas, validando o que já havia garantido a Constituição de 1988. Ampliou a certificação quilombolas e a regularização fundiária, dando acesso a várias melhorias como o abastecimento de água via PAC-FUNASA, o programa Minha Casa, Minha Vida, o programa Luz para Todos e garantia da tarifa social, assistência técnica e extensão rural, construção de escolas quilombolas, aprovação das Diretrizes Curriculares para Educação Escolar Quilombola, Programa Brasil Quilombola, dentre outras medidas. Apesar dessas políticas públicas, a justiça social em relação à educação não foi efetivada, as comunidades permanecem com problemas em relação à educação, com ensino de má qualidade, com a maioria dos professores sem capacitação adequada e em número insuficiente para atender à demanda, além da infraestrutura das escolas serem inadequadas (SANTOS et. al, 2019). Poucas comunidades têm unidade educacional com o ensino fundamental completo e quase $75 \%$ delas encontra-se no Nordeste.

De acordo com Santos et al. (2019),

\begin{abstract}
As comunidades quilombolas foram durante muito tempo territórios arbitrariamente esquecidos ou silenciados. Nem os governos nem as policies communities se dedicaram a produzir diagnósticos e avaliações precisos sobre essa realidade. Avançar nessa agenda se faz necessário, pois é no terreno do secundário, do negligenciável, que se ancoram práticas racistas legitimadas pelo Estado (SANTOS et al., 2019, p. 5).
\end{abstract}

As dificuldades que passam as comunidades quilombolas são históricas e têm suas raízes nas opressões provocadas pelo racismo. Não pode ser esquecido o fato da negação de educação gratuita e de qualidade à grande parcela da população, excluindo principalmente os afrodescendentes, os quais correspondem ao maior número de estudantes que não completam a escolarização mínima necessária até os dias atuais.

Segundo dados do IBGE em 2019, a desigualdade racial afeta também o processo de escolarização, pois a taxa nacional de analfabetismo entre as pessoas brancas de 15 anos ou com mais de idade era de $3,6 \%$, enquanto entre as pessoas pretas ou pardas era de $8,9 \%$ (TORKANIA, 2020). Quando se avalia a população com 60 anos ou mais, essa taxa aumenta consideravelmente, pois foi identificado que $9,5 \%$ dos brancos não sabem ler ou escrever, mas em relação aos pretos e pardos esse percentual é de $27,1 \%$, ou seja, três vezes maior e é mais acentuado na região Nordeste que tem o maior percentual de analfabetos com 15 anos ou mais $(13,9 \%)$, sendo de 37,2\% o percentual relativo à população com 60 anos ou mais (TORKANIA, 2020). Esse é um significativo fator que impede a continuação do processo de escolarização e, por consequência, a melhoria das condições de vida e de oportunidades para população negra. 
A Educação, enquanto dispositivo de emancipação, permite a realização potencial de transformar vidas e tornar as pessoas agentes sociopolíticos, combatentes na luta antirracista. Por essa razão, Santos et al. (2019, p. 5) alerta que “[...] avançar nessa agenda se faz necessário, pois é no terreno do secundário, do negligenciável, que se ancoram práticas racistas legitimadas pelo Estado". Desse modo, não basta dar acesso aos socialmente sub-representados, mas, também, promover uma mudança significativa nas estruturas educacionais, inclusive em termos de práticas e condutas racializadas e excludentes, assinalando a visibilidade, o enfrentamento e a transformação das instituições (WALSH, 2012). O conhecimento permite a realização potencial de transformar e trazer a valorização da diversidade racial, possibilita a visualização da necessidade do combate ao preconceito, à discriminação e à todas as formas de opressão.

\section{Metodologia}

Trata-se de estudo exploratório, descritivo, com abordagem quanti-qualitativa e do tipo documental, realizado no âmbito da UFBA. Optou-se pelo estudo de caso por considerar relevante compreender as características únicas do processo de inclusão, por meio de cotas específicas para o público-alvo em uma universidade pública da Bahia. De acordo com Yin (2001), “[...] o poder diferenciador do estudo [de caso] é a sua capacidade de lidar com uma ampla variedade de evidências" e, assim, possibilitar compreender as particularidades do objeto de estudo e suas dimensões.

O acesso aos dados foi obtido do Sistema Acadêmico da Universidade (SIAC). Desse modo, foi verificado o quantitativo de estudantes matriculados por meio dos sistemas de cotas para remanescentes de comunidades quilombolas, a oferta de vagas e a concorrência, as opções de campos de estudo e áreas de interesse, egressos e dados de evasão dos alunos, desde a implantação das cotas em 2004. Foram eleitos para esta pesquisa todos os cursos de graduação presenciais e na modalidade a distância, incluindo bacharelados, licenciaturas e cursos superiores de tecnologia. A análise dos dados foi realizada a partir do cálculo de proporção no Excel do Microsoft Office.

Quanto ao procedimento de análise, consistiu em uma análise documental, cujas operações sistemáticas (codificação de informação e estabelecimentos de categorias) visaram analisar e estudar vários documentos (relatórios gerados pelo SIAC) no intuito de descobrir as circunstâncias com as quais podem estar relacionados (RICHARDSON, 2012). A categoria e subcategorias preestabelecidas, a partir do referencial normativo e norteador da pesquisa, foram: estudantes remanescentes de comunidades quilombolas (categoria principal), número de 
matriculados por curso, tipo de curso e área do conhecimento, egressos e evasão (subcategorias).

Mediante o exposto, essa análise foi desenvolvida considerando as cinco dimensões propostas por Cellard (2008): contexto de produção dos documentos, seus autores, a confiabilidade e autenticidade textuais, a natureza do texto, os conceitos-chaves e a lógica interna do texto. E nossa pesquisa sucedeu por meio do estabelecimento da análise em três etapas: (1) análise preliminar dos documentos e sua organização, considerando uma leitura exaustiva do material; (2) a exploração e sistematização dos dados, tendo como referência as categorias anteriormente definidas; (3) tratamento dos resultados, resultante das etapas antecessoras, no esforço de identificar e dar interpretações condizentes com a temática e o problema da pesquisa, utilizando estratégias de indução e dedução (CELLARD, 2008).

\section{Resultados e discussão}

As ações afirmativas são necessárias para o combate ao racismo, que continua atuante na contemporaneidade e de forma cada vez mais complexa (CAMPOS, 2017). Esse fator justifica a importância de estudos com essa temática como parte da luta antirracista e do reconhecimento e valorização dos grupos sub-representados pelo poder político e econômico. Ademais, os reflexos da consolidação das relações baseada na distinção racial persistem na atualidade atingindo vários institutos sociais, entre eles o sistema educacional brasileiro que reproduz práticas discriminatórias.

Todavia, o processo de expansão e democratização do acesso à educação superior iniciada pelo Governo Federal a partir de 2003 foi uma sequência de investimentos que priorizou a inserção de grupos sub-representados nos espaços universitários e possibilitou mudar em parte o cenário educacional brasileiro, ampliando as relações intergrupos sociais (ALMEIDA FILHO et al, 2005).

Considerando as ações supracitadas que impactaram no acesso e na expansão das vagas ofertadas pela UFBA, obteve-se informações relevantes no que tange à inserção dos quilombolas desde a implantação das cotas raciais específicas, conforme detalhado nas categorias seguintes: 


\section{A. Evolução do número de participações no processo seletivo}

O meio de acesso as vagas de graduação na UFBA atualmente é o Sistema de Seleção Unificada do Governo Federal (SISU). Contudo, no que se refere à seleção para as vagas dedicadas aos remanescentes de comunidades quilombolas, a seleção manteve-se realizada pela própria Universidade. A partir de 2012, a UFBA passou a adotar a avaliação realizada via Exame Nacional do Ensino Médio (ENEM) como parte também deste processo de seleção. Nota-se, como se pode observar no Gráfico 2, que no período de transição do formato de seleção, entre 2012 a 2013, houve uma queda no número de inscritos.

Gráfico 2 - Evolução dos números de inscritos: quilombolas e aldeados indígenas

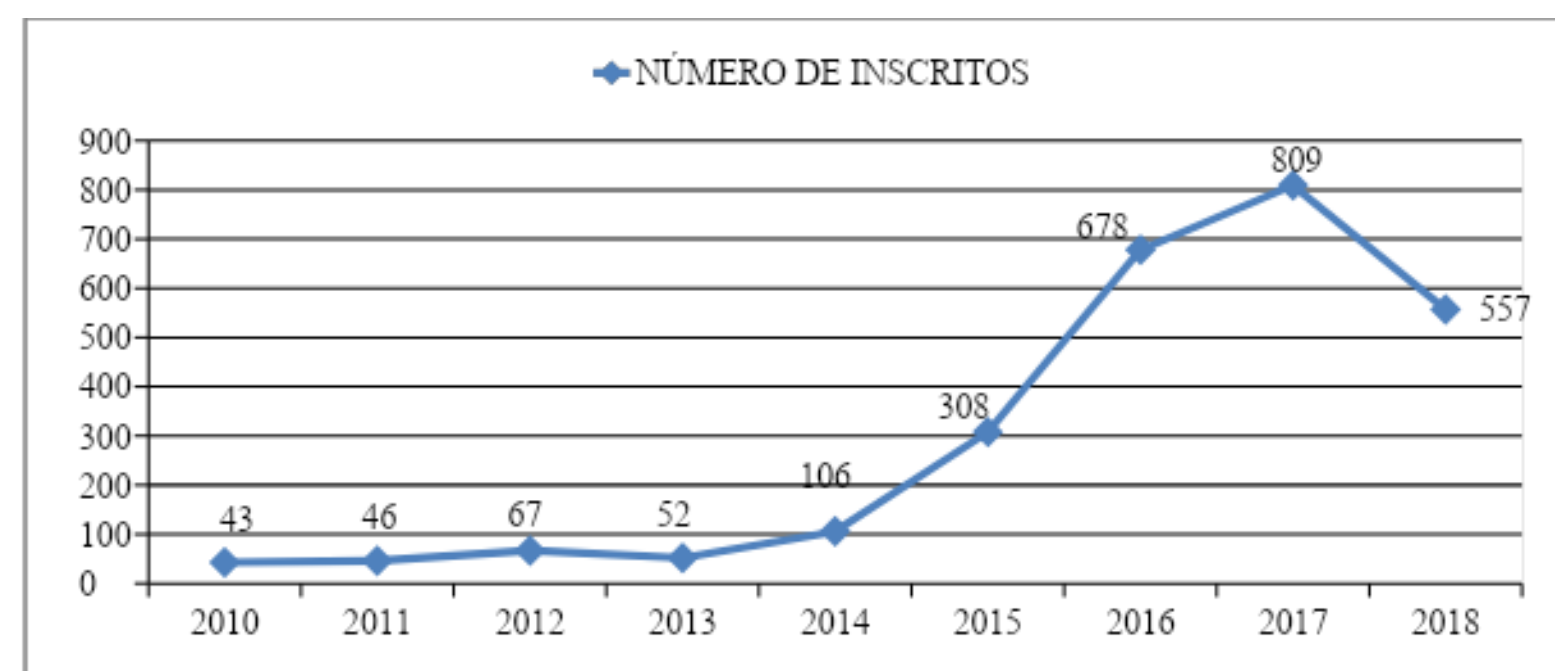

Fonte: Elaborado pelas autoras (2021).

Atribui-se essa redução na procura, ao possível período de adaptação ao novo sistema de seleção, bem como, às possíveis dificuldades desses candidatos em participar via ENEM ou até mesmo, a falta de informação sobre a necessidade de recorrer ao ENEM para participar do certame. Todavia, a partir de 2015, o número de inscritos cresce em mais de $200 \%$ em relação ao período anterior e se mantém em crescimento constante. Ressalta-se que esses dados são referentes às entradas em dois semestres por ano, exceto 2018, cujos dados somente foram divulgados até o primeiro semestre, fator que justifica o número menor de inscrito em relação ao ano anterior, mas que se considera de crescimento elevado, pois equivale a mais de $50 \%$ do quantitativo referente ao total de dois semestres do ano antecessor. Destaca-se também, que a procura maior é pelo curso de Medicina, curso tradicionalmente concorrido em todas as categorias de cotas e ampla concorrência. 


\section{B. Evolução do número de ingressos}

$\mathrm{O}$ acesso por meio das cotas para remanescentes de comunidades quilombolas foi aprovado pela UFBA em 2004 e entrou em vigor na seleção do ano seguinte (UFBA, 2004). Portanto, os dados demonstrados no Gráfico 2 são referentes ao número de ingressos cotistas dessa categoria e foram disponibilizados a partir de 2005.1. No Gráfico 3, especificou-se a evolução do acesso dos cotistas, a saber:

Gráfico 3 - Evolução das matrículas por ano: quilombolas

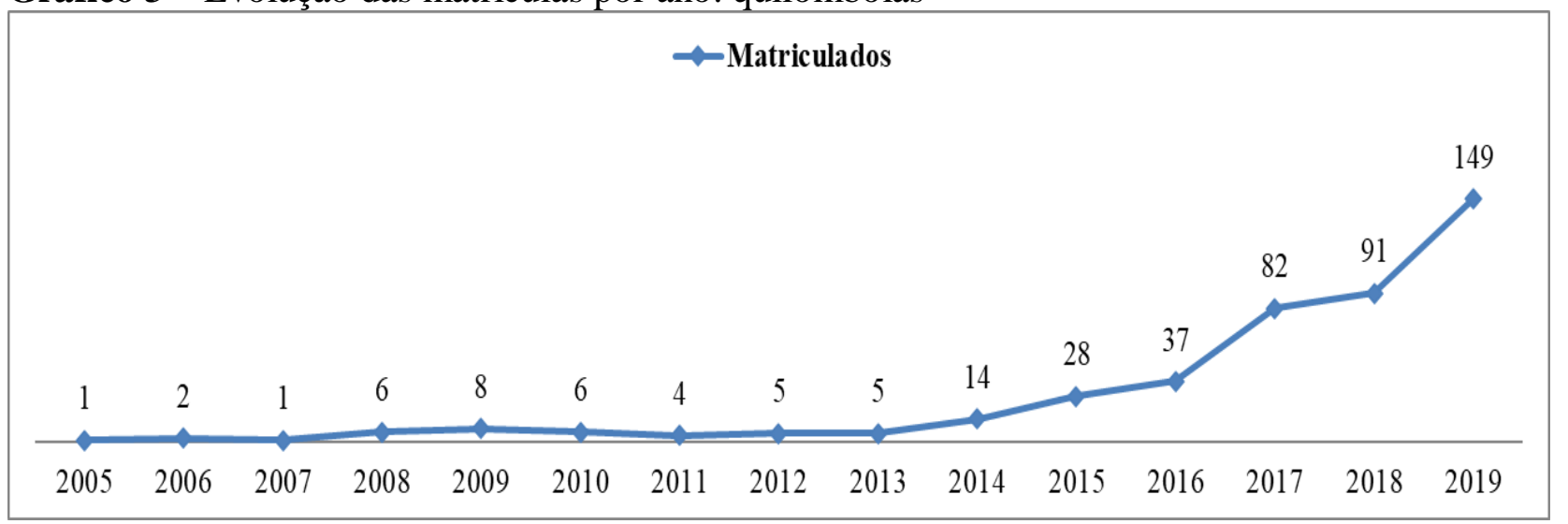

Fonte: Elaborado pelas autoras.

Desse gráfico, pode-se perceber que o número de ingressos se manteve com baixa entrada, oscilando entre 1 e 8 ingressos até o ano de 2013. A partir de 2014, o número de matrículas aumentou, passando de 5 em 2013 para 14 matriculados em 2014, um salto de quase 200\% em relação a 2013. No último certame, foram 148 matrículas, que, comparado a 2014, é um aumento significativo de ingressos por esse tipo específico de cotas. Do somatório final de todas as matrículas desde 2005.1 até 2019.2, totalizaram 439 estudantes remanescentes de comunidades quilombolas.

\section{Dados sobre conclusão, permanência e evasão}

Com base na análise das tabelas fornecidas pelo sistema acadêmico da Universidade, foi possível classificar por categorias a depender da situação de matrícula do estudante. Essas categorias são dadas pelo próprio sistema, que indicou ter ao longo do processo de inclusão dos estudantes cotistas em questão: desde 2005 até 2019.2. A situação é a seguinte: 
Tabela 1 - Situação de matrícula: remanescentes de comunidades quilombolas (2005 a 2019.2)

\begin{tabular}{ll|l}
\hline \multicolumn{2}{l|}{ Situação de matrícula } & Quantitativo \\
\hline 1. & Rec. Mat-Aus. Insc.Disciplinas & 4 \\
2. & Graduado & 29 \\
3. & Vaga Cancelada por Decisão Judicial & 0 \\
4. & Mudança de Habilitação & 1 \\
5. & Matrícula ativa & 391 \\
6. & Aguardando Colação de Grau & 3 \\
7. & Decurso Prazo Máximo & 1 \\
8. & Integrado à UFOB - Lei 12.825 & 2 \\
9. & Mudança de Curso & 7 \\
10. & Cumpriu Grade Curricular & 1 \\
\hline Total & & $\mathbf{4 3 9}$ \\
\hline
\end{tabular}

Fonte: Elaborado pelas autoras (2021).

No decurso dos últimos anos, após a inclusão das cotas para remanescentes quilombolas, considerando o quantitativo total de 439 matrículas, somente 4 (quatro) estudantes tiveram suas matrículas canceladas por falta de inscrição em disciplinas, ou seja, por evasão, sendo 4 que cursavam respectivamente os cursos de Ciências da Computação, Administração, Farmácia e Medicina Veterinária. Quanto aos números de conclusão, graduaram no total 29 estudantes, sendo a maioria conclusões anterior a 2014.

Conforme demonstrado no Gráfico 4, até 2013 foram 23 graduações e 4 evasões. Considerando que até 2013 havia somente 38 matrículas, pode-se perceber que $60,5 \%$ dos matriculados de 2005 a 2013 já estavam diplomados. A partir das matrículas de 2014.1 até 2019.1, nenhum estudante havia evadido ou obteve a matrícula cancelada por descumprimento às normas acadêmicas. 
Gráfico 4 - Comparativo entre conclusão e evasão

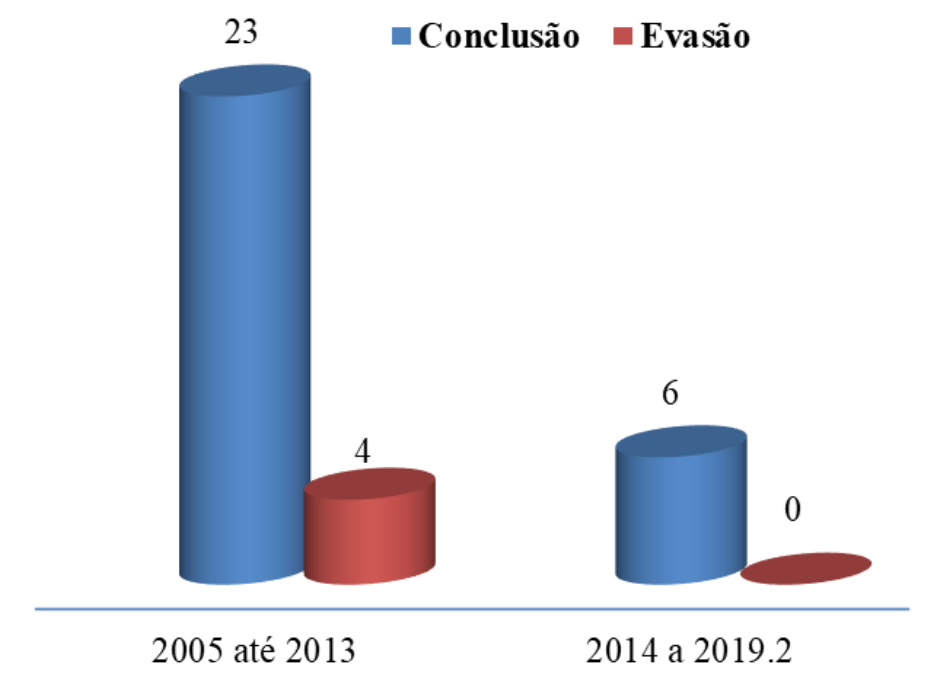

Fonte: Elaborado pelas autoras (2021).

\section{Cursos e áreas de interesse}

Para análise dessa categoria, optou-se por enquadrar as escolhas formativas dos estudantes em áreas do conhecimento de forma que possibilitassem melhor a compreensão dos resultados. A primeira opção foi dispor os cursos em Áreas do Conhecimento (Grande Área), conforme estabelecido pela Universidade (UFBA, 2020) e representado no gráfico seguinte:

Gráfico 5 - Número de estudantes e área do conhecimento

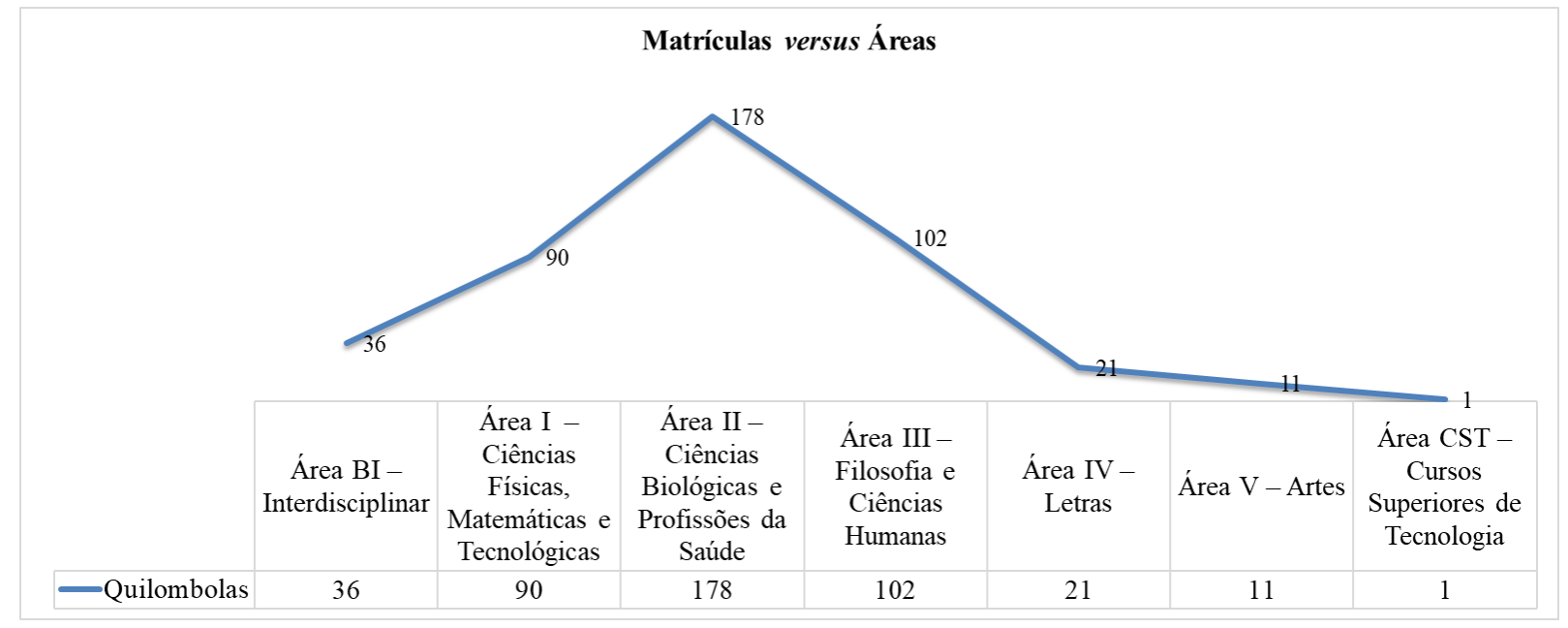

Fonte: Elaborado pelas autoras (2021).

Tornou-se possível identificar que para ambos os grupos há uma maior predominância nas escolhas formativas para os cursos da Área II - Ciências Biológicas e Profissões da Saúde (cerca de 40,5\% das matrículas) e Área III - Filosofia e Ciências Humanas (23,2\% das 
matrículas). As áreas de menor interesse são Área V - Artes e Área CST - Cursos Superiores de Tecnologia, que contam com 11 (onze) e 1 (um) matriculados respectivamente. No que concerne a Área II, os cursos com maior número de matriculados são: Farmácia (25), Enfermagem (21), Medicina (20), Psicologia (19), Ciências Biológicas (19) e Nutrição (18). Na área III a predominância está nos cursos de Letras (21), Pedagogia (15) e Direito (12). O curso com maior número de matrículas na Área I é Geografia (13) e na Área V o curso de Dança (9). Os cursos com menor número de matrícula são Artes Cênicas (1), Design (1), Engenharia de Agrimensura e Cartografia (1), Gênero e Diversidade (1) e Superior de Tecnologia em Transporte Terrestre (1). Quanto à habilitação dos cursos (Bacharelado e Licenciatura), identificou-se após análise da Tabela 3 que a maior parte está cursando o bacharelado, isto é, 334 estudantes e apenas 105 matriculados em licenciaturas.

Tabela 2 - Número de matriculados por habilitação: remanescentes de comunidades quilombolas (2005 a 2019.2)

\begin{tabular}{l|l}
\hline Modalidade do Curso & Total (439) \\
\hline Bacharelado & 334 \\
\hline Licenciatura & 105 \\
\hline
\end{tabular}

Fonte: Elaborado pelas autoras.

Subentende-se que para esses estudantes a carreira técnica se mostra mais atrativa do que a formação para o magistério, compreende-se que a escolha para o Bacharelado é equivalente a $76 \%$ (setenta e seis por cento) das escolhas formativas desses estudantes em comparação com as licenciaturas que é de $24 \%$ (vinte e quatro por cento).

Gráfico 6 - Número de matriculados por curso/habilitação

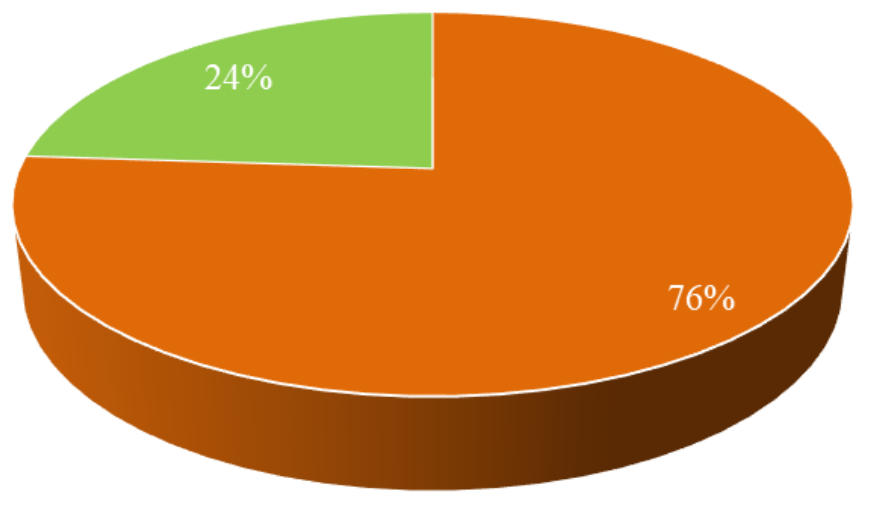

- Bacharelado - Licenciatura

Fonte: Elaborado pelas autoras (2021). 
Mediante os resultados apresentados, reconhece-se a fundamental relevância das políticas públicas, ao aproximar o Estado das populações remanescentes de quilombos e ao ser basilar no processo de reconhecimento e inserção das comunidades nos espaços nos quais mantinham-se apartadas por um processo histórico de exclusão (LARCHERT; OLIVEIRA, 2013), principalmente quanto ao acesso à educação superior.

\section{Conclusões}

A universidade pública, por sua função social, deve atuar como promotora no desenvolvimento de ações que visem à emancipação intelectual dos cidadãos, sendo um instrumento de que contribua para a ascensão da parcela da população historicamente excluída do acesso ao ensino acadêmico. Acredita-se, portanto, que ao se engajar na oferta de ações afirmativas que visem à inclusão de estudantes por meio das cotas raciais, a universidade está exercitando o seu dever de instituição cidadã e colaborando para o fortalecimento da democracia e da justiça social.

A UFBA tem possibilitado que esses cidadãos também tenham o direito de ocupar o espaço universitário que tradicionalmente era ocupado pelas classes e grupos mais privilegiados em poder político e econômico a partir de 2005 com as cotas raciais específicas para quilombolas, grupo étnico que carrega o estigma da exclusão social, fruto de um processo de colonização. Neste contexto, a UFBA tem se tornado mais democrática e mais plural.

Considerando os tempos formativos distintos para cada curso e a singularidade da itinerância formativa de cada estudante, conclui-se que as taxas de permanência dos estudantes são satisfatórias, uma vez que só há registro acadêmico de 4 estudantes evadidos dentro de um grupo de 439 estudantes em 14 anos da implantação desse tipo específico de cotas. Também compreende-se que a taxa de conclusão é exitosa, pois dentro do tempo formativo de 8 anos com um grupo de 38 estudantes, 23 completaram suas graduações, significando $60,5 \%$ de conclusão. Além disso, nota-se que os cursos tradicionalmente ocupados pelas elites brancas da sociedade, como Medicina e Direito, estão sendo espaços de formação para remanescentes de comunidades quilombolas, fator de importante transformação na vida dessas pessoas, consequentemente de suas famílias, comunidades de inserção e do cenário educacional brasileiro.

Contudo, compreende-se que a limitação dessa pesquisa está em identificar se a permanência desses estudantes tem de fato proporcionado uma devida inclusão igualitária quando comparados aos sujeitos dos demais grupos étnicos-raciais que fazem parte do escopo 
estudantil. Para tanto, será necessário ouvir a percepção desses estudantes e o significado para eles de fazer parte da Universidade.

Cabe destacar ainda que os cortes orçamentários na educação superior a partir de 2016 e os que foram intensificados também a partir de 2019 impactaram diretamente na continuidade das políticas de ações afirmativas, principalmente para os remanescentes quilombolas que necessitam de auxílio estudantil para a sua permanência na universidade.

Desse modo, pode-se concluir que as ações afirmativas ultrapassam medidas paliativas de concessões de benefícios pecuniários, requer uma reparação, um reconhecimento e valorização histórica, política, cultural e de identidade. Exigem mudanças político-pedagógicas que possam promover oportunidades de emancipação intelectual e socioeconômica para todos os cidadãos provenientes de uma sociedade multicultural e pluriétnica. Por essa razão, torna-se necessário reivindicar a manutenção da universidade pública, plural e inclusiva.

\section{Referências}

ALMEIDA FILHO, N. et al. Ações afirmativas na universidade pública: o caso da UFBA. Salvador: Centro de Estudos Afro-Orientais, 2005.

AGÊNCIA IBGE NOTÍCIAS. PNAD - Contínua 2017: número de jovens que não estudam nem trabalham ou se qualificam cresce 5,9\% em um ano. Disponível em:

https://agenciadenoticias.ibge.gov.br/agencia-sala-de-imprensa/2013-agencia-denoticias/releases/21253-pnad-continua-2017-numero-de-jovens-que-nao-estudam-nemtrabalham-ou-se-qualificam-cresce-5-9-em-um-ano. Acesso em: 14 de ago. 2019.

BRASIL. Casa Civil Subchefia para Assuntos Jurídicos. Decreto n. 5.051, de 19 de abril de2004.Promulga a Convenção ${ }^{\circ} 169$ da Organização Internacional do Trabalho - OIT sobre Povos Indígenas e Tribais. Diário Oficial da União, Brasília, DF, 20. abr. 2004. Disponível em: http://www.planalto.gov.br/ccivil_03/_ato2004-2006/2004/decreto/d5051.htm. Acesso em: 12 de ago. 2019.

BRASIL. Lei 12.711, de 29 de agosto de 2012. Dispõe sobre o ingresso nas universidades federais e nas instituições federais de ensino técnico de nível médio e dá outras providências. Diário Oficial da União, Brasília, DF, 30. ago. 2004. Disponível em: http://www.planalto.gov.br/ccivil_03/_ato2011-2014/2012/lei/112711.htm. Acesso em: 11 de ago. 2019.

CAMPOS, L. A. Racismo em três Dimensões: Uma abordagem realista-crítica. Rev. bras. Ci. Soc., São Paulo. v. 32, n. 95, 2017. Disponível em: http://www.scielo.br/scielo.php?script=sci_arttext\&pid=S0102$69092017000300503 \& \operatorname{lng}=$ pt\&nrm=iso. Acesso em11 ago. 2019.

CELLARD, A. Análise documental. In: POUPART, J. et al. A pesquisa qualitativa: enfoques epistemológicos e metodológicos. Trad. Ana Cristina Nasser. 
Petropólis: Vozes, 2008. p. 295-316.

CORREIOS. MEC amplia bloqueio de recursos para a Ufba: corte pode passar de $\mathrm{R} \$ 55$ milhões.2019. Disponível em: https://www.correio24horas.com.br/noticia/nid/mec-ampliabloqueio-de-recursos-para-a-ufba-corte-pode-passar-de-r-55-milhoes/. Acesso em: 16 ago. 2019.

DINIZ-PEREIRA, J. E.; SOARES, L. J. G. Formação de Educadoras/es, diversidade e compromisso social. Educ. rev., Belo Horizonte, v. 35, 2019. Disponível em: http://www.scielo.br/scielo.php?script=sci_arttext\&amp;pid=S010246982019000100207\&amp;lng=pt\&amp;nrm=iso\&gt. Acesso em: 29 jul. 2019.

FUNDAÇÃO CULTURAL PALMARES. Comunidades certificadas. In: Certificação Quilombola, 2019 Disponível em: http://www.palmares.gov.br/?page_id=37551. Acesso em: 12 ago. 2019.

FURTADO, M. B.; PEDROZA, R. L.S., ALVES, C. B. Cultura, identidade e subjetividade quilombola: uma leitura a partir da psicologia cultural. Psicologia \& Sociedade, v. 26, n. 1, p. 106-115, 2014.

LARCHERT, J. M.; OLIVEIRA, M. W. de. Panorama da educação quilombola no Brasil. Políticas Educativas, Porto Alegre, v.6, n. 2, p. 44-60, 2013. Disponível em: https://seer.ufrgs.br/Poled/article/viewFile/45656/28836. Acesso em: 30 jun. 2019.

QUIJANO, A. Colonialidade do poder, Eurocentrismo e América Latina. In: LANDER, E. (org.). A colonialidade do saber: eurocentrismo e ciências sociais. Perspectivas latinoamericanas. Buenos Aires: CLACSO, Consejo Latino Americano de Ciencias Sociales, setembro, 2005. Disponível em: http://bibliotecavirtual.clacso.org.ar/clacso/sursur/20100624103322/12_Quijano.pdf. Acesso em: 11 ago. 2019.

RICHARDSON. R. J. Pesquisa social: métodos e técnicas. 3 ed. São Paulo: Atlas, 2012.

SANTOS, E. S. et al. Oferta de Escolas de Educação Escolar Quilombola no Nordeste Brasileiro. Educação \& Realidade, Porto Alegre, v. 44, n. 1, 2019.

UNIVERSIDADE FEDERAL DA BAHIA (UFBA). Conselho de Ensino, Pesquisa e Extensão. Resolução $n^{o} 1$, de 26 de julho de 2004. Altera a Resolução 01/2002 do CONSEPE. Estabelece reserva de vagas na seleção para os cursos de graduação da UFBA realizada através do Vestibular. 2004. Disponível em: https://ufba.br/sites/portal.ufba.br/files/Resolu\%C3\%A7\%C3\%A3o\%2001.2004.pdf. Acesso em: 09 ago. 2019

UNIVERSIDADE FEDERAL DA BAHIA (UFBA). Conselho de Ensino, Pesquisa e Extensão. Resolução n. 03/2012. Altera o Art. $3^{\circ}$ e o Art. $5^{\circ}$ da Resolução $n^{\circ}$ 01/2004 do CONSEPE. 2012. Disponível em: https://ingresso.ufba.br/sites/ingresso.ufba.br/files/resolucao_03.2012_1.pdf. Acesso em: 09 ago. 2019

UNIVERSIDADE FEDERAL DA BAHIA (UFBA). Cursos. Disponível em: https://ufba.br/cursos. Acesso em: 30 abr. 2020. 
WALSH, C. Interculturalidad crítica y pedagogía decolonial: apuestas (des)de el in-surgir, reexistir y re-vivir. Revista de Educação Técnica e Tecnológica em Ciências Agrícolas. Seropédica - RJ, v.3. n.6, p. 25-42, 2012.

YIN, R. K. Estudo de caso: planejamento e métodos. 2 ed. Tradução Daniel Grassi, Porto Alegre: Artmed, 2001. 